\title{
No Happy Endings: Practicing Care in Troubled Times
}

\author{
Angela Molloy Murphy
}

Angela Molloy Murphy, EdD, is a lecturer in early childhood education with the Melbourne Graduate School of Education at University of Melbourne. She has been an early childhood educator since 1990, founding schools of her own, including her current school, Rowanberry School, in 2006. Angela serves as a materials specialist with Inventing Remida Portland Project at Portland State University and recently completed her doctoral studies in the curriculum and instruction EdD program. Her doctoral research engages critical posthumanism and new materialism to research the relational material-discursive encounters that are present in children's everyday narrative processes. Email: angela.molloymurphy@unimelb.edu.au Twitter: @23angelas

This article uses a multispecies inquiry to research the relations between human children and other-than-human animals, specifically, a piglet, in a home-based early childhood setting. The focus of this work is to activate critical posthumanism and common worlds scholarship to consider the ethics of relations of care in which the fate of the cared-for is uncertain. I draw on Puig de la Bellacasa's theory of care to consider the implications of our school community's care for the piglet, which was offered freely and in full awareness of uncertain consequences and precarious futures.

Key words: child-animal relations; theory of care; multispecies inquiry; common worlds
When our care for another cannot ensure them a "happy ending," how does our care matter? This question has developed over 20 years of providing care for nonhumans alongside humans in a home-based preschool. In that time, we have cared for dozens of chickens, rabbits, guinea pigs, chinchillas, cats and dogs, a hedgehog, and even an injured squirrel. Our rabbits and chickens have been killed by racoons or possums on countless occasionsviolent deaths that leave us feeling temporarily shattered. There have also been the inconspicuous deaths-when a child runs to the chicken coop to collect eggs and discovers that a chicken has quietly died in the night. Each of these deaths has affected us in unique ways and caused me to revisit this enduring question regarding the value of our care for creatures with precarious futures. There was, however, one particular encounter with an animal that sparked a deeper inquiry into this wondering. That encounter is the subject of this article.

One summer my 11-year-old daughter and I visited a petting area at a local organic farm to feed the goats and the piglets. One of the piglets fell asleep in her arms and we were both quite moved. The farmer in the petting area, visiting from his own farm in Sherwood, Oregon, told us about a program they were starting where one could foster a newborn pig that required special care to survive. He told us a story about runts who were successfully fostered until they were large enough to get their share of food and survive the weight of their mother when nursing. The experience with the piglet paired with the story had done its job ... We added our names to the list of potential foster families to contact when an endangered runt was born on the farm.

Within a few weeks we received a call from the farmer, who was looking for a foster family to provide immediate care for a piglet. He told me he had acquired the animal from a sister farm in central Oregon. The piglet was suffering from respiratory issues due to smoke inhalation, and when he and his brother were delivered to the farm, he was chronically sneezing and his eyes were caked shut. The smallest in the newly assembled drove, he was the last to eat, and as a result was languishing. The farmer had been looking for a placement for the piglet with no success. Even with human intervention, his survival was uncertain. 
We were torn. My daughter and I had collectively imagined a sweeter, more innocent scenario that positioned us as rescuers of a fragile but otherwise healthy newborn pig in need of care. As we described the pictures we had unknowingly been holding in our imaginations and contrasted it with the reality of the current situation, I realized that I had been envisioning our role as foster care providers as epitomized by a particular scene in one of my favourite childhood books, Charlotte's Web. In this dramatic passage, Fern bravely steps in to save the runt of a new litter of piglets from her father's axe. Her father argues that killing the piglet is the humane choice because he is likely to die anyway. Fern vows to personally provide care for the animal to save his life. From her compassion for and dedication to the animal she would call Wilbur, a beautiful multispecies friendship emerges. Fern's care for Wilbur enables him to peacefully live out his twilight years on the farm surrounded by human and animal companions, essentially providing him with a "happy ending."

Although the pull of this fictional narrative was a powerful one, I recognized that the present moment required ethically informed action as opposed to romanticized imaginaries. Fires had been burning throughout central Oregon all summer. People and animals had lost their lives and been otherwise injured or displaced. Every living thing in the region was impacted. In this context, providing care for a damaged animal with an uncertain future held what Maria Puig de la Bellacasa (2017) refers to as "vital material implications-for human and nonhuman worlds" (p. 42). After grappling with the ethics of the circumstances with my daughter, we made arrangements to drive out to the Sherwood farm and pick up the piglet to bring home.

The animal we would call Moon was a cross between three small breeds, a runt American Guinea hog, KuneKune, and Juliana. He was bred to stay small-small enough to live on an urban farm, but big enough to eventually slaughter if deemed appropriate. We were given an instruction sheet and training time with the farmer, who wanted to ensure we had adequate space and resources available to care for a growing baby pig, because he had experienced problems with fostering piglets to people who were ill equipped for the demands of the job. In fact, while we were talking to the farmer, a woman approached him to return a piglet she had taken home only days before. The scene was strange and unforgettable: a well-polished woman in business dress marching up the dusty path of the rural farm with a piglet in a box, "returning" the animal as if it were an unsatisfying item of clothing. "We heard screaming all night," she told the farmer. "It was the most terrible sound you can imagine." I was distressed by the experience she described, and equally disturbed by my association with her. I wanted to view my role as a caregiver or companion, not a customer.

Looking back on this moment, I realize that although bringing an agitated piglet back to a farm in a box did not look like care as I had imagined it, or perhaps had idealized it, it may have been the most caring, ethically sound move the woman could make. When the farmer returned from his conversation with her, he made a disparaging comment about how some people foster baby pigs for the Instagram photo opportunities and are not prepared for the real work it will entail. My daughter and I exchanged a guilty glance with one another. Just that morning we had spoken about posting photos of the piglet on Instagram.

Referring to the ethics of caring practices, de la Bellacasa (2017) states, "We do not always know in advance what world is knocking, or what will be the consequences" (p. 91). This is the sense I had as my daughter and I drove home with the piglet in a bright pink cat carrier. He brayed loudly the whole way, terrified, and surprisingly loud. The "unnatural" feeling of the situation was undeniable. Still a very young pig, he required bottle feeding every four hours with warmed goat milk. I enlisted the help of my daughter and her neighbourhood friends for this task ... an easy recruitment. At this stage in his development the piglet was not unlike a newborn human, tiny and vulnerable, and we all soon discovered that bottle feeding him evoked tremendous feelings of care. I set up a playpen in the lower level of our house where my preschool classroom resides. The picture was both tender and absurd, and 
blurred the lines commonly drawn between human and nonhuman infancies-a piglet in a playpen, surrounded by baby blankets and stuffed toys.

Common worlds scholars have argued that it is "timely for early childhood scholars to make a greater contribution to broader 'more than-human' or post-humanist conversations that have been gathering momentum in the social sciences over the last couple of decades" (Taylor, Pacini-Ketchabaw, \& Blaise, 2012, p. 81). Multispecies inquiries (e.g., Hohti \& Tammi, 2019; Lloro-Bidart, 2018; Pacini-Ketchabaw, Taylor \& Blaise, 2016; Taylor \& Pacini-Ketchabaw, 2015) offer one compelling approach to attend to research with the more-than-human. For example, Fikile Nxumalo and Veronica Pacini-Ketchabaw (2017) enact multispecies ethnography in considering the implications of classroom pet pedagogies; they call for "radically different ways of viewing our relationships with more-than-human others" (p. 1423). This critical posthumanist practice (Barad, 2011; Braidotti, 2013; LloroBidart, 2018; Murris et al., 2018; Rice, 2016; Rotas, 2015; Snaza, 2015) advances a framework of relational learning with material, place, human, and nonhuman actors as opposed to a child-centered and exclusively human social framework. Experimental multispecies/posthumanist methodologies work to shift our perspective away from solely human ones and make space for nonanthropocentric ways (Bell \& Russell, 2000) of seeing and being both in classrooms and in the larger world.

Informed by critical posthumanism, as well as my experiences with the multispecies nature of children's everyday school lives (Pederson, 2010), I initiated a multispecies inquiry into child-animal relations between the human children in my neighbourhood and at my preschool and the piglet we collectively cared for. It was September, the beginning of our school year, when Moon came to know the preschool children. Several of the children had experience with a "rescue" animal in a school context (Molloy Murphy, 2018), as our community had previously provided care for an injured squirrel. Consequently, we held an institutional awareness about what it meant to provide care for an animal that is resistant to physical touch and other signifiers of care and affection (Gunnarsson, 2018) that we might be accustomed to with domesticated pets. Further, we had established an "ethic of kinship and care" (Rose, 2017) within our multispecies classroom community that provided a hospitable climate for an injured animal.

We watched the piglet carefully, "attuning and attending" (Rautio, 2017) to his ways. We discovered that the piglet enjoyed roaming around in our play yard on sunny days, comfortable in the contact zone (Haraway, 2008) where children, chickens, and the occasional dog come together. We learned to sit on the ground and let the piglet nuzzle up to us rather than trying to pick him up as one would a dog or cat. He struggled against being cradled, even for bottle feeding. In fact, he resisted every anthropomorphic fantasy I had unconsciously developed from idyllic depictions of care, such as the classic illustrations in Charlotte's Web. In one such image, for example, Fern cradles Wilbur the piglet in her arms, holding his head upright as one would bottle feed a human baby. Moon, not being a storybook piglet, instinctively wanted to stand upright and drink from a bottle as he would nurse from his mother.

The oldest children invented a way to scoop Moon up with a blanket to reduce the kicking and squirming when we carried him, which was as little as possible. He ran away when approached by humans. If we needed to move him back inside the house, for instance, we had to corner him to pick him up. He habitually rubbed his side against the trunk of a tree, which led to bald spots and badly scraped skin. Unsure of the practical need for this activity, we began putting a dog sweater on him during our outside play to prevent him from further wounding himself. In essence, we were attending to the problem of "how to care" (de la Bellacasa, 2017) for the piglet in the context of this particular time and place, in a multispecies coexistence and without the guidance of a pig mother. Moon, in turn, quickly adapted to his human, predominantly child caregivers, who offered him vegetables when he climbed on their laps. On chilly days he burrowed inside children's coats, poking his head out only to eat. 
There were multiple ethico-political complexities to consider regarding our care of the piglet. In our common worlds, where past, present, and future lives are entangled (Blaise, Hamm, \& Iorio, 2016), the intentional centering of curriculum which is "otherwise" (Nxumalo, Vintimilla, \& Nelson, 2018) from safe and sterilized curricular engagements is a critical aspect of the work of mattering with children. Thus, when uncomfortable discussions about the cause of the piglet's predicament or his potential future arose, we attended to the children's inquiries, resisting the urge to look away (Haraway, 2016) from the matters of concern (Iorio, Hamm, Parnell, \& Quintero, 2017; Latour, 2004) that made their way into the classroom along with the piglet.

For example, climate change was a prominent factor in the fires that burned that summer along the west coast of the United States, compromising the air quality in California and Oregon and rendering conditions harmful. Though the broad concept of climate change was abstract to the children, the topic of air quality was tangible, as it held immediate material consequences for our multispecies community. Even in our urban neighbourhood, far from the fires, there were days we could smell smoke and were advised to stay indoors due to compromised air quality.

In addition to this, the children were aware that the piglet had been evacuated from his original farm due to poor air quality caused by wildfires. Looking at his eyes and listening to his laboured breathing, it was apparent that his exposure to smoke had damaged him. A few of the children had a schema regarding the dangerous potential wildfires have for vulnerable populations because they had grandparents living in California, where the fires were the worst. One child shared his understanding of the predicament in saying, "My Oma lives in California. She can't go outside on the red days."

Moreover, children openly wondered about the piglet's future-of what would become of him when we returned him to the farm. During a discussion about farms and farming practices at a class meeting, a 5-year old stated plainly, "Bacon comes from pigs." This declaration hung heavily in the air. I confirmed the child's statement; unable to offer assurances or escape the plain fact. Bacon comes from pigs, and the animal we had come to care for was a pig. Truthfully, I was given no guarantees about the piglet's future; the farmer's answers to my queries had been decidedly vague. I surmised that it was possible we were caring for Moon until he was healthy and strong enough to be butchered on the farm. If our care of the piglet was part of an economic and practical scheme to prepare him for his eventual slaughter and consumption, were we not actively participating in it by providing excellent care for him, for example, by feeding him well and causing him to trust humans?

Joan Tronto (2010) might suggest that our care of the damaged animal was serving to "maintain, continue and repair 'our world' so that we [could] live in it as well as possible" (p. 16). I find hope in this proposition. Conversely, I consider the possibility that our care practices contributed to objectifying and commodifying farming practices (Singleton \& Law, 2013) and reinforced colonizing, extractive human-animal relations of power (Cutter-McKenzieKnowles et al., 2018). It seems more likely, however, that each of these propositions coexist despite their multiple "tensions and contradictions" (Puig de la Bellacasa, 2017). Ultimately, our care of the piglet led us to stay with the trouble (Haraway, 2016) of forest fires and animal/farm/food assemblages, enabling these "matters of concern" to also become "matters of care" (Puig de la Bellacasa, 2011) for our multispecies community.

Moon grew quickly from a tiny piglet with silky black fur to a large, bristly boar whose hunger seemed insatiable. I was no longer able to feed him solely on vegetable scraps and resorted to processed pellets from a local feed store. The farmer specifically warned against this practice as it was likely to "prematurely fatten him up." My choice to supplement the pig's diet with commercial feed was burdensome-I worried that I was promoting the piglet's slaughter by causing him to gain weight. Winter was approaching and we were spending less time outdoors due to cold weather and rain. The piglet was often muddy and was not getting enough exercise. He began to look 
preposterous and overgrown in the baby blue playpen. The classroom perpetually stank of urine regardless of how often we changed the bedding.

Just as the practical care demanded by a growing pig in a small house began to feel unmanageable, our allotted three-month foster period came to an end. It was a very emotional drive to the farm. The farmer assured me I could come back and visit, saying, "Pigs are smart animals. He'll remember you." This was both reassuring and somehow terrifying. I felt as if my responsibility to the pig did not end-would never end, despite his uncertain future.

I return to my enduring question: When our care for another cannot ensure a "happy ending," how does our care matter? Informed by the theory of care proposed by Puig de la Bellacasa (2017), I now regard our care for the piglet as an act of "cultivating a speculative commitment to contribute to livable worlds" (p. 67), a conscious striving to live as well as possible (Tronto, 2010) on a damaged planet. Our care for Moon was freely undertaken (Hoy, 2004), meaning it was "not forced upon [us] by a moral order" (Puig de la Bellacasa, 2017, p. 70), and was offered in full awareness of uncertain consequences and precarious futures. I cannot claim it was valiant or innocent, or that it ensured the piglet's survival. However, this caring assemblage produced ways of relating with other species that are otherwise (Nxumalo et al., 2018) than comfortable human-rescue narratives (Taylor, 2017) with promises of mutual salvation. These old, familiar storylines ring hollow in our current era of great planetary suffering. Thus, our care mattered in that it was an ethical and political practice in living well with human and nonhuman others (Taylor \& Giugni, 2012) when no guarantees of salvation were possible. Our shared futures are always already uncertain. We care anyway. 


\section{References}

Barad, K. (2011). Posthumanist performativity: Toward an understanding of how matter comes to matter. Signs, 28(3), 801-831. https:// doi.org/10.1086/345321

Bell, A., \& Russell, C. (2000). Beyond human, beyond words: Anthropocentrism, critical pedagogy, and the poststructuralist turn. Canadian Journal of Education, 25(3), 188-203. https://doi.org/10.2307/1585953

Blaise, M., Hamm, C., \& Iorio, J. M. (2016). Modest witness (ing) and lively stories: Paying attention to matters of concern in early childhood. Pedagogy, Culture, \& Society, 25(1), 31-42. https://doi.org/10.1080/14681366.2016.1208265

Braidotti, R. (2013). The posthuman. Polity.

Cutter-Mackenzie-Knowles, A., Malone, K., \& Barratt Hacking, E. (2018). Research handbook on childhoodnature. Springer International Handbooks of Education.

Gunnarsson, K. (2018). Responding with care: A careful critical approach within educational health promotion. Reconceptualizing Educational Research Methodology, 9(1). https://doi.org/10.7577/rerm.2699

Haraway, D. J. (2008). When species meet. University of Minnesota Press.

Haraway, D. J. (2016). Staying with the trouble: Making kin in the Chthulucene. Duke University Press.

Hohti, R., \& Tammi, T. (2019). The greenhouse effect: Multispecies childhood and non-innocent relations of care. Childhood, 26(2). https://doi.org/10.11770907568219826263

Iorio, J. M., Hamm, C., Parnell, W., \& Quintero, E. (2017). Place, matters of concern, and pedagogy: Making impactful connections with our planet. Journal of Early Childhood Teacher Education, 38(2), 121-135. https://doi.org/10.1080/10901027.2017.1306600

Latour, B. (2004). Why has critique run out of steam? From matters of fact to matters of concern. Critical Inquiry, 30(2), 225-248. https:// doi.org/10.1086/421123

Lloro-Bidart, T. (2018). A feminist posthumanist multispecies ethnography for educational studies. Educational Studies, 54(3), $253-270$. https://doi.org/10.1080/00131946.2017.1413370

Molloy Murphy, A. (2018). (Re)considering squirrel: From object of rescue to multispecies kin. Journal of Childhood Studies, 43(1), 60-67. https://doi.org/10.18357/jcs.v43i1.18265

Murris, K., Reynolds, R.-A., \& Peers, J. (2018). Reggio Emilia inspired philosophical teacher education in the Anthropocene: Posthuman child and the family (tree). Journal of Childhood Studies, 43(1), 15-29. https://doi.org/10.18357/jcs.v43i1.18262

Nxumalo, F., \& Pacini-Ketchabaw, V. (2017). "Staying with the trouble" in child-insect-educator common worlds. Environmental Education Research, 23(10), 1414-1426. https://doi.org/10.1080/13504622.2017.1325447

Nxumalo, F., Vintimilla, C. \& Nelson, N. (2018). Pedagogical gatherings in early childhood education: Mapping interferences in emergent curriculum. Curriculum Inquiry, 48(4), 433-453. https://doi.org/10.1080/03626784.2018.1522930

Pacini-Ketchabaw, V., Taylor, A., \& Blaise, M. (2016). Decentering the human in multispecies ethnographies. In C. A. Taylor \& C. Hughes (Eds.), Posthuman research practices in education (pp. 149-167). Springer.

Pedersen, H. (2010). Animals in schools: Processes and strategies in human-animal education. Purdue University Press.

Puig de la Bellacasa, M. (2011). Matters of care in technoscience: Assembling neglected things. Social Studies of Science, 41(1), 85-106. https://doi.org/10.1177/0306312710380301

Puig de la Bellacasa, M. (2017). Matters of care: Speculative ethics in more than human worlds. University of Minnesota Press.

Rautio, P. (2017). "A super wild story": Shared human-pigeon lives and the questions they beg. Qualitative Inquiry, 23(9), $722-731$. https://doi.org/10.11771077800417725353 
Rice, S. (2016). The educational significance of human and non-human animal interactions: Blurring the species line. Palgrave Macmillan.

Rose, D. B. (2017). Shimmer: When all you love is being trashed. in A. Tsing, H. Swanson, E. Gan, \& N. Bubandt (Eds.), Arts of living on a damaged planet: Ghosts and monsters of the Anthropocene (pp. 51-63). Minnesota University Press.

Rotas, N. (2015). Ecologies of praxis: Teaching and learning against the obvious. In N. Snaza \& J. A. Weaver (Eds.), Posthumanism and educational research (pp. 91-103). Routledge.

Singleton, V., \& Law, J. (2013). Devices as rituals: Notes on enacting resistance. Journal of Cultural Economy, 6(3), 259-277. https://doi.or g/10.1080/17530350.2012.754365

Snaza, N. (2015). Toward a genealogy of educational humanism. In N. Snaza \& J. A. Weaver (Eds.), Posthumanism and educational research (pp. 17-29). Routledge.

Taylor, A. (2017). Beyond stewardship: Common world pedagogies for the Anthropocene. Environmental Education Research, 23(10), 1448-1461. https://doi.org/10.1080/13504622.2017.1325452

Taylor, A., \& Giugni, M. (2012). Common worlds: Reconceptualising inclusion in early childhood communities. Contemporary Issues in Early Childhood, 13(2), 108. https://doi.org/10.2304ciec.2012.13.2.108

Taylor, A., \& Pacini-Ketchabaw, V. (2015). Learning with children, ants, and worms in the Anthropocene: Towards a common world pedagogy of multispecies vulnerability. Pedagogy, Culture, \& Society, 23(4), 507-529. https://doi.org/10.1080/14681366.2015.1 $\underline{039050}$

Taylor, A., Pacini-Ketchabaw, V., \& Blaise, M. (2012). Children's relations to the more-than-human world. Contemporary Issues in Early Childhood, 13(2), 81-85. https://doi.org/10.2304ciec.2012.13.2.81

Tronto, J. (2010). Creating caring institutions: Politics, plurality, and purpose. Ethics and Social Welfare, 4(2), 158-171. https://doi.org/1 $\underline{0.1080 / 17496535.2010 .484259}$ 